\title{
Los intérpretes griegos en Heródoto y Jenofonte ${ }^{1}$
}

\section{The Greek Interpreters in Herodotus and Xenophon}

\author{
José David BECERRA IsLAS \\ https://orcid.org/0000-0002-2027-3570 \\ Universidad Nacional Autónoma de México, México \\ jdavidbi@outlook.com
}

\begin{abstract}
RESUMEN: Este artículo centra su atención en la figura del traductor-intérprete

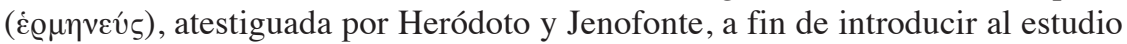
de los posibles tipos de traducción oral que se llevaban a cabo entre griegos y bárbaros en el antiguo Oriente. Si bien el presente análisis se limita a estos dos autores como fuentes, es éste el primer trabajo que examina particularmente las formas en que se practicaba la actividad interpretativa. Gracias al enfoque con el que se abordan los testimonios de Heródoto y Jenofonte, también ha sido posible determinar las características y el tipo de traducción oral empleado por los intérpretes, según las situaciones en que fueran requeridos sus servicios para ayudar a establecer la comunicación entre los griegos y el mundo que conocían.
\end{abstract}

Palabras clave: traducción, intérprete, griegos, Heródoto, Jenofonte

ABSTRACT: In this article we focus on the character of the translator-interpreter

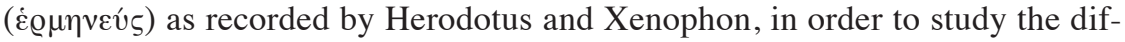
ferent types of oral translations achieved between Greeks and barbarians in Ancient East. Although our analysis is limited to these two sources, we think in our work are for the first time examined the ways in which such activity was practiced. Here we consider how testimonies of Herodotus and Xenophon have contributed to define the main lines and types of oral translations used by the interpreters, according to the situations in which their services were required.

\footnotetext{
${ }^{1}$ Quiero agradecer a Alejandra Ramírez Pro, excelente colaboradora y colega, historiadora clásica en ciernes, todo su apoyo incondicional para la redacción de este trabajo. Sus acertadas observaciones, comentarios y correcciones siempre me son de utilidad invaluable. 
KeYwORDS: Translation, Interpreter, Greeks, Herodotus, Xenophon

ReCiBIDO: 21/10/2019 • ACEPTADO: 12/12/2019 • Versión FinAL: 19/12/2019

\section{PREMisa}

La traducción es una de las actividades más complejas de la mente humana $\mathrm{y}$, acaso, una de las más importantes en tanto que ha servido como vehículo "para la propagación de la cultura, para la creación y el desarrollo de nuevas literaturas y para el enriquecimiento de las lenguas utilizadas para traducir".

El origen de la traducción es tan lejano, tan anterior al mito fundacional de la diversificación de las lenguas narrado en el Génesis, ${ }^{3}$ que se pierde en la inmensa oscuridad de la prehistoria, del tiempo, y su protohistoria quizá deba buscarse muchísimos milenios atrás, cuando el hombre fue conformando distintos sistemas de comunicación; entre ellos, por supuesto, primero el de la lengua oral y luego el de la escrita. El ser humano, entonces, tuvo la necesidad de comunicarse intralingüísticamente, pero también de manera interlingüística, por eso adquirió la capacidad de aprender lenguas distintas a la suya para entenderlas, interpretarlas y traducirlas, en un principio y durante muchos milenios, de forma oral. ${ }^{4}$

Lamentablemente, a la fecha, no se ha escrito una protohistoria de la traducción ${ }^{5}$ que proporcione un corpus de testimonios antiguos que permita estudiar el desarrollo histórico de la fase oral de la traducción desde sus inicios hasta nuestros días, pues la mayoría de los esfuerzos por historiar dicha actividad se ha enfocado más en su fase escrita y no tanto en la interpretativa; de tal modo que lo que pueda decirse del proceso de la interpretación en ese periodo "protohistórico", es decir, previo a la aparición de testimonios concretos verificables referentes a la traducción oral, muchas veces estará más bien basado en la suposición.

${ }^{2}$ García Yebra 1994, p. 11.

${ }^{3}$ Gen., 11, 1-9. Para un breve análisis de la influencia del mito de la Torre de Babel y la llamada cuestión babélica en la historia de la traducción, cf. Jiménez 2013, p. 5 ss.

${ }^{4}$ Respecto al surgimiento de la traducción, Steiner 2011, p. 4, plantea lo siguiente: "Si bien es cierto que traducimos a cada instante cuando hablamos o recibimos indicaciones en nuestra propia lengua, es obvio que la traducción en un sentido más amplio y común surge cuando dos idiomas se encuentran. Que sea preciso que hubiera dos idiomas distintos, que hubiera, en un cálculo aproximado, más de veinte mil que se hubiesen hablado en este pequeño planeta, es la cuestión babélica. ¿Por qué el Homo sapiens sapiens, genética y fisiológicamente uniforme en casi todos los aspectos, sujeto a idénticas posibilidades de evolución y a las mismas limitaciones biológicas y ambientales, habla miles de lenguas incomprensibles entre sí, algunas de las cuales están separadas por unos cuantos kilómetros?"

${ }^{5}$ García Yebra 1994,p. 11. 
La figura y actividad del traductor-intérprete de la Antigüedad no ha merecido suficiente atención de parte de los historiadores modernos, ni de lingüistas, filólogos o traductólogos, y en general se habla poco de ellos o simplemente se les deja pasar de largo sin reconocer ni valorar la importancia que debieron tener como intermediarios que facilitaron el contacto de hombres que hablaban lenguas diferentes y como mediadores para la conformación de las culturas antiguas. ${ }^{6}$ No obstante, tenemos algunos testimonios antiguos conservados por los griegos, principalmente Heródoto y Jenofonte, quienes hacen referencia a esa primera etapa traductora y dan constancia de la actividad interpretativa del غ̇

Es casi un lugar común decir que los griegos no tradujeron a su lengua nada de la literatura de otros pueblos con los que compartieron la cuenca del Mediterráneo y una buena parte de las tierras orientales, sin contar a los habitantes del lado occidental europeo. El que no conservemos restos literarios de traducciones al griego hechas por griegos, no significa que éstos desconocieran la traducción escrita; supongamos, pues, que la conocían pero no la practicaban. ${ }^{7}$ Pienso, más bien, porque no he hallado otra explicación, que en sus andanzas orientales no encontraron alguna literatura bárbara que, según ellos, fuera digna de ser trasladada y conservada en algún dialecto heleno. ${ }^{8}$

Resulta difícil pensar, siquiera imaginar, que el hombre griego, curioso por naturaleza, desarrollado en una zona geográfica cultural y lingüísticamente diversa, no hablara al menos una lengua extranjera que le permitiera relacionarse y comerciar con los bárbaros orientales. El bilingüismo, e incluso el plurilingüismo, si no era una habilidad difundida en el grueso de la población griega, sí debió estar presente por lo menos en algunos de sus grupos sociales, quizá principalmente entre comerciantes y militares quienes constantemente debían entablar comunicación con pueblos de habla distinta a la suya.

\footnotetext{
${ }^{6}$ Una de las dificultades que enfrenté para la elaboración de este artículo fue la falta de una bibliografía especializada sobre el tema; no hay libros ni artículos en español o en otra lengua moderna, o al menos yo no los encontré, que estudien exclusiva y directamente el desarrollo, influencia o importancia histórica de la traducción oral en la Antigüedad. En cuanto a la interpretación o traducción oral en el mundo moderno, con algunos vistazos al mundo antiguo, apenas es rescatable el capítulo "Cuestiones de confianza: la larga sombra de la traducción oral", en Bellos 2012, pp. 13-146. Para más referencias bibliográficas en torno a la traducción interpretativa u oral, puede verse el artículo de Ortega Arjonilla (2009) que recoge datos de obras sobre el tema y que se publicaron en español entre 1996 y 2009; es oportuno insistir en que los textos ahí mencionados no abordan el estudio de los intérpretes o de la traducción oral en la antigüedad clásica.

${ }^{7}$ Sabemos que Heródoto no fue muy receptivo del uso de la escritura, cf. Signes 2004, p. 106.

${ }^{8}$ La Septuaginta no debe considerarse porque, aun cuando está vertida del hebreo y arameo al griego, no es una traducción realizada por griegos de nacimiento, sino por judíos helenizados.
} 


\section{HERÓdOTO, HisTORIAS}

Sabemos que los griegos, de cuando en cuando, tuvieron el interés de aprender alguna de las lenguas de los pueblos bárbaros con quienes mantuvieron contacto, ${ }^{9}$ pero que era más factible que estos últimos aprendieran el idioma griego se atestigua en una noticia transmitida por el propio Heródoto en sus Historias; allí cuenta que el rey Psamético, una vez que se hizo dueño de Egipto:

[1] a los jonios y a los carios que lo habían ayudado, dio unos terrenos que quedaban enfrente uno de otro, pues el Nilo estaba en medio de ellos, y fueron llamados campamentos; les dio estos terrenos y les entregó todo cuanto les había prometido. [2] Y además les confió unos niños egipcios para que les enseñaran la lengua griega; los actuales intérpretes en Egipto descienden de aquellos niños que aprendieron la lengua. ${ }^{10}$

Por el testimonio citado, es evidente que Psamético ${ }^{11}$ reconocía la importancia de la comunicación interlingüística entre griegos y egipcios para facilitar el desarrollo del intercambio comercial y cultural; mas este interés por la intercomunicación no fue privativo de los egipcios. Pensemos en la enorme cantidad de tablillas e inscripciones cuneiformes bilingües y hasta trilingües, que han llegado a nosotros de esas culturas orientales situadas entre los ríos Tigris y Éufrates, en Asia Menor, y el río Nilo, al norte de África, respectivamente, conocidas como "culturas fluviales" o del "Creciente fértil", que conformaron un verdadero territorio babélico debido a la multitud de lenguas que llegaron a hablarse en esa región: sumerios, hetitas, acadios, cananeos, fenicios, egipcios, babilonios, y muchos más, que nos han dejado evidencias escritas mostrando una intensa actividad traslaticia entre ellos, principalmente comercial, pero también literaria. ${ }^{12}$

${ }^{9}$ Tucídides (I, 137, ed. 1988) y más tarde Plutarco (Them., 29, 5, ed. 1969) atestiguan que Temístocles estudió persa durante un año para poder comunicarse él mismo de manera fluida con Artajerjes; es decir, suponemos que sin la mediación de un intérprete. Dice Plutarco en ese

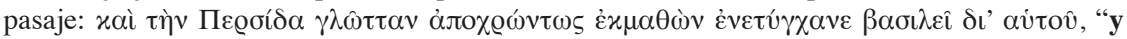
cuando aprendió suficiente persa él mismo se presentaba ante el Rey". Temístocles, junto con Falino, del que se hablará más adelante, son dos casos curiosos de griegos que aprendieron una lengua extranjera, a saber, el persa. A partir de aquí, las traducciones de los fragmentos citados y las negritas que aparezcan en ellas son mías, a no ser que se indique lo contrario.

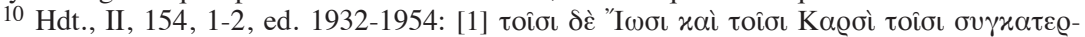

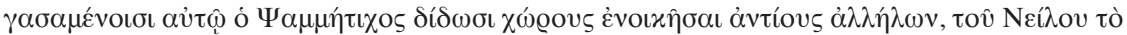

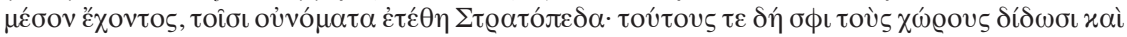

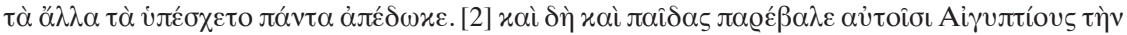

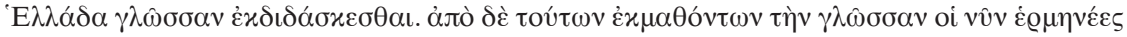

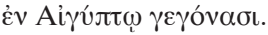

${ }^{11} \mathrm{La}$ fecha probable de Psamético I es la del 664 a. C.

12 García Yebra 1994,pp. 11 ss. 
Sin duda, Heródoto, al ser un viajero curioso, como afirman algunos, ${ }^{13}$ compuso sus Historias valiéndose de sus predecesores, a saber, los logógrafos jonios y sus crónicas de países lejanos, y, entre éstos, de forma particular, cita por su nombre a Hecateo de Mileto en repetidas ocasiones; ${ }^{14}$ no obstante, el historiador da forma a sus relatos principalmente a partir de lo que vio y de lo que le contaron sus informantes, según deja constancia en varios lugares de su relato; es decir, se basa en la transmisión oral, en las narraciones que le hacían aquellos con quienes entraba en contacto durante sus viajes por tierras bárbaras: algunos griegos comerciantes o mercenarios que se habían desplazado hacia las costas del Mar Negro o al sur de Italia, con los que evidentemente no tuvo problemas de comunicación.

¿Cuánto sabía Heródoto de alguna lengua extranjera? En un artículo muy interesante, Thomas Harrison se pregunta sobre la concepción de las lenguas extranjeras que tenía el historiador. ${ }^{15}$ Es muy probable, señala Harrison, ${ }^{16}$ que Heródoto no supiera ni hablar ni escribir en otra lengua distinta al griego, le sorprende el hecho de que, siendo de la ciudad de Halicarnaso, no fuera capaz de entender el cario y que incluso se refiera a él como una lengua bárbara, según se desprende del relato que el propio Heródoto consigna en VIII, 135, 2, cuando el enviado de Mardonio para consultar distintos oráculos, Mis de Europo, entra al santuario de Apolo Ptoo y el sacerdote hace los vaticinios en una lengua bárbara y no en griego. ${ }^{17}$

¿Cómo hizo entonces dicho historiador para nutrirse de información cuando viajaba entre tribus bárbaras y se internó en tierras escitas? ¿O cuando se dirigió al Alto Egipto? Sin duda recurrió a intérpretes, por lo general bárbaros que hablaban griego, como es el caso de los niños egipcios, formados como intérpretes-traductores. Tal debió ser la importancia de estos غ̇ que, de acuerdo con Heródoto, eran una de las siete castas egipcias: "Hay siete castas de egipcios, y se llaman de esta manera: sacerdotes, guerreros, boyeros, porquerizos, mercaderes, intérpretes y pilotos. Estas son las castas de los egipcios, y reciben sus nombres debido a sus oficios". 18

Es interesante la mención que hace en este fragmento de los intérpretes como una de las siete castas egipcias porque ya se reconoce, al menos entre los egipcios, a la traducción oral, la interpretación, como un oficio para el

${ }^{13}$ Albaladejo 2007, p. 268.

${ }^{14}$ Hdt., II, 143, 1; V, 36, y VI, 137, ed. 1932-1954.

15 Harrison 1998.

${ }^{16}$ Harrison 1998, p. 3.

${ }^{17}$ Harrison da otros ejemplos sacados de las Historias con los que pone en duda el conocimiento de Heródoto de las lenguas bárbaras.

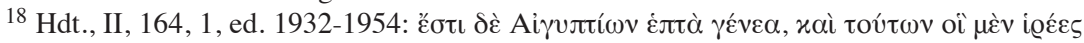

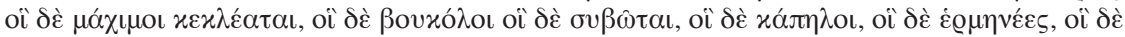

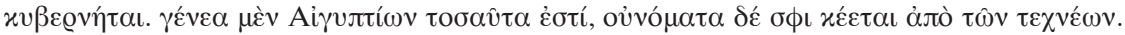


que, quien se dedicara a él, debía prepararse desde niño; es decir, entre los egipcios el oficio de intérprete no sólo estaba profesionalizado, sino que además era un oficio de vida.

Se sabe que Heródoto usó con frecuencia a esa primera casta egipcia para obtener información acerca de las costumbres de ese pueblo y consignarlas en su obra, por lo menos así se lee en varias partes del libro II de sus Historias: "me informaron [...], me dijeron [...]", "escuché decir a los sacerdotes $[\ldots]$; los sacerdotes me dijeron [...]", etcétera. ${ }^{19}$ Lo que no se sabe con certeza es si esos sacerdotes hablaban griego o también utilizaban un intérprete.

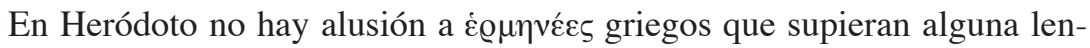
gua bárbara, y las menciones directas que hace de los intérpretes bárbaros que sabían griego tampoco son muchas, pero a partir de ellas puede deducirse, más o menos, qué técnica utilizaban para realizar su actividad interpretativa: si de manera sucesiva o consecutiva, simultánea o por susurro. ${ }^{20}$

Así, por ejemplo, cuando el historiador refiere que Creso, el último rey de Lidia, estaba a punto de morir en la hoguera que Ciro mandó construir para tal efecto, el lidio pronunció entre sollozos hasta tres veces el nombre de Solón:

Y Ciro que escuchaba estas cosas ordenó a los intérpretes que preguntaran a Creso que a quién invocaba y ellos acercándose le preguntaron. Y preguntaban a Creso que guardaba silencio, pero, luego de haber sido presionado, dijo: "A uno

${ }^{19}$ Son varios los lugares a lo largo de las Historias en los que podemos leer las fórmulas señaladas. Para el lector interesado, proporciono algunas referencias del libro II que pueden llamar su atención: 2,$5 ; 3,3 ; 4,1 ; 79,3 ; 102,2 ; 142,1$.

${ }^{20}$ La traducción escrita y la oral o interpretativa son dos formas distintas de una misma actividad que se basa en dos operaciones básicas: descodificación de un mensaje producido en una lenga original (LO) o de partida (LP), y la reformulación de ese lenguaje en una lengua terminal (LT), de llegada (LL) o meta (LM). Evidentemente, los procesos cognitivos de ambos tipos de traducción son distintos y cada uno conlleva sus propias particularidades y dificultades. Refiriéndonos en exclusiva a la traducción oral, es necesario que, en su proceso traductivo, el intérprete observe rasgos paralingüísticos tales como acento del hablante, entonación, características dialectales, pronunciaciones anómalas o irregularidades gramaticales, entre otros muchos factores o incidencias del habla o del sujeto que se traduce. Actualmente la traductología distingue varios tipos y subtipos de traducción oral (cf. Hurtado Albir 2001, pp. 80 ss.). Aquí, siguiendo el criterio básico de clasificación de las modalidades de traducción oral que se funda en el momento de reformulación del texto de llegada con respecto al texto de partida (cf. Jiménez Ivars 1999), sólo me interesa destacar tres. 1) La modalidad sucesiva o consecutiva es aquella en la que el texto de partida emitido verbalmente es reformulado en una LT tras paradas constantes y producción oral posterior; es decir, el emisor habla en LO y se detiene para dar tiempo a que el intérprete reformule su mensaje en LT. 2) La modalidad simultánea es aquella en la que el texto de partida emitido verbalmente es reformulado en una LT al mismo tiempo de su emisión; esto es, mientras el emisor habla en LO, el intérprete reformula, al mismo tiempo, su mensaje en LT. 3) La traducción en susurro es una variante tanto de la modalidad sucesiva como de la consecutiva y puede desarrollarse como cualquiera de esas dos. La diferencia está en que se realiza de manera simultánea o sucesiva pero al oído del receptor. 
que yo hubiera deseado a cualquier precio llevara sus palabras a todos los monarcas". Pero como se expresaba de un modo confuso para ellos, le volvieron a preguntar lo que quería decir. ${ }^{21}$

Poco más adelante, "Creso dijo estas cosas a Ciro que las escuchaba de los intérpretes". ${ }^{22}$ En el libro III, en medio del excurso sobre el poder de las costumbres en el mundo, agrega Heródoto que "después de esas cosas, Darío convocó a los indios llamados calatias, que se comen a sus progenitores, y en presencia de los griegos, que seguían la conversación por medio de un intérprete, les preguntó [...]", 23 y en el mismo libro, cuando se entabla un diálogo entre Darío y Silosonte, se lee: "El portero hizo pasar a Silosonte $\mathrm{y}$, deteniéndose ante todos, los intérpretes le preguntaban quién era y qué había hecho para afirmar que era un bienhechor del rey". ${ }^{24}$

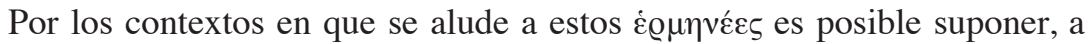
riesgo de estar equivocados, que la traducción interpretativa que hacían era de carácter sucesivo, aquella en la que el intérprete va traduciendo por fragmentos las conversaciones que se dan entre los interlocutores. Pensemos en las modernas entrevistas de radio o televisión.

No hay más casos explícitos en las Historias que se refieran a este tipo de traductores, quizá por las razones que señala Schrader en su nota al pasaje de Heródoto, la cual, por su relevancia en el tema que se aborda, reproduzco a continuación:

La mención en este pasaje a los intérpretes salpica de colorido oriental la historia de Silosonte, ya que tales personajes eran una especie de secretarios que hablaban la inmensa mayoría de las lenguas del imperio y que eran utilizados en las audiencias del rey a sus diferentes súbditos; además de estar encargados de llevar a cabo un primer interrogatorio a toda persona que deseara ver al rey (en ese sentido, estaban a las órdenes del "introductor de mensajes"; cf. nota III 176). No obstante, Heródoto olvida en muchas ocasiones aludir a la intervención de intérpretes, cuando tal intervención sería de esperar (por ejemplo, en la conversación mantenida entre Darío y Silosonte en el capítulo anterior), pues, en este tipo de anécdotas de carácter moralizante y dudoso valor histórico, parece imaginarse a los interlocu-

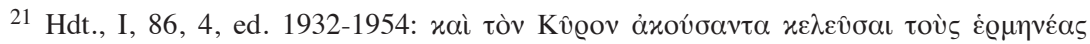

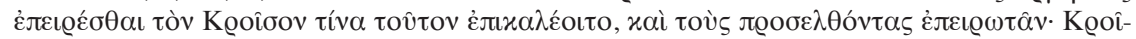

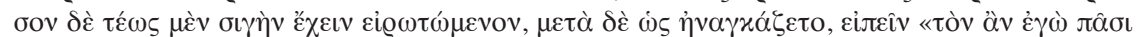

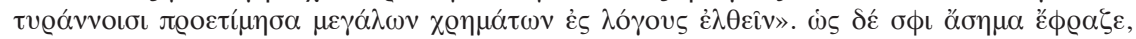

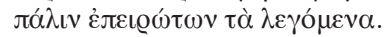

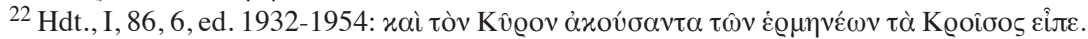

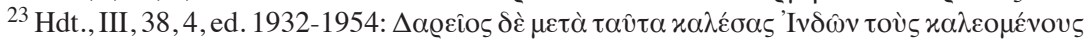

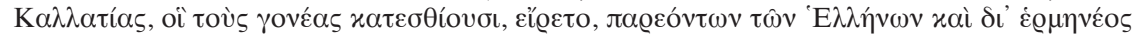
$\mu \alpha v \theta \alpha v o ́ v \tau \omega v \tau$ ¿े $\lambda \varepsilon \gamma \delta ́ \mu \varepsilon v \alpha[\ldots]$.

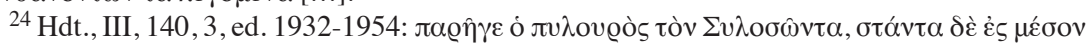

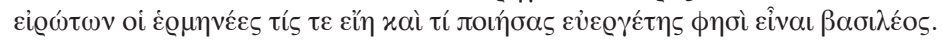


tores, aun siendo de distinta nacionalidad, hablando la misma lengua; igual que ocurre en Homero con troyanos y griegos. ${ }^{25}$

A este apunte de Carlos Schrader yo le añadiría que las omisiones que se hacen de los $\dot{\varepsilon} \varrho \mu \eta v \varepsilon ́ \varepsilon \varsigma$ en Heródoto son, quizá, porque su trabajo era ya tan cotidiano y estaban tan acostumbrados a convivir con ellos, que su oficio ya no causaba asombro, como tampoco nos lo causa hoy, por ejemplo, la traducción escrita, a la que nosotros estamos más acostumbrados. ${ }^{26}$ Evidentemente, Heródoto estaba más cercano a la oralidad no sólo como medio de transmisión de información y de cultura, sino también como medio de conservación de ésta.

Que los intérpretes orientales que dominaban el griego, o alguna otra lengua de aquellas zonas geográficas, sean con frecuencia omitidos como tales, puede ser demostrado a partir de que Heródoto no siempre se refiere a ellos como $\dot{\varepsilon} \varrho \eta \eta v \dot{\varepsilon} \varsigma$ y simplemente alude al conocimiento que alguien, o algún pueblo, puede tener de otra lengua, como ocurre cuando Cambises está preparando su expedición contra Cartago: "Y cuando Cambises consideró oportuno enviar a sus espías, en ese instante hizo traer de la ciudad de Elefantina, de donde son los hombres ictiófagos, a los que conocían la lengua etiópica". ${ }^{27} \mathrm{El}$ ejemplo sugiere la necesidad de hurgar con mayor atención en las Historias a fin de encontrar casos similares que ayuden a formarnos una mejor idea de la función e importancia de la traducción oral en la Antigüedad.

\section{JENOFONTE, ANÁBASIS}

Con Jenofonte ocurre algo más o menos parecido. En la Anábasis relata las penurias que sufrieron los diez mil mercenarios griegos en su retirada a lo largo de casi $4000 \mathrm{~km}$ por tierras asiáticas, cruzando muy distintos pueblos, lenguas y culturas. En el texto jenofontiano se encuentran alusiones a muchos intérpretes, con numerosas intervenciones, que conocían lenguas muy variadas. Pigres era el intérprete persa usado por Ciro para dar sus instrucciones militares a los generales griegos: "Y después de ponerse delante de todos, detuvo su carro frente a la mitad de la falange, y envió a su intérprete Pigres ante los generales griegos para ordenarles que adelantaran sus

\footnotetext{
${ }^{25}$ Heródoto 1979, p. 249, n. 720.

${ }^{26}$ Bellos 2012, p. 133.

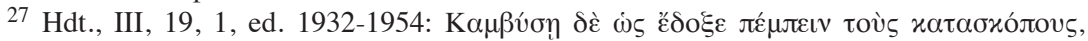

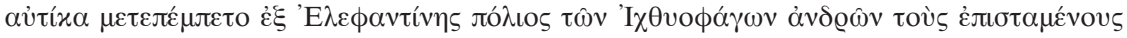

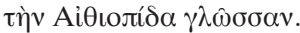


armas y rodearan toda la falange", 28 así como Pategías, quizá el más famoso persa al servicio de Ciro mencionado en el que probablemente es uno de los momentos más emocionantes de la Anábasis:

Y ya era el medio día, cuando se llena el mercado y estaban muy cercanos los campamentos en los que descansarían, cuando en el instante Pategías, un persa muy allegado a Ciro, apareció cabalgando a la fuerza un caballo que sudaba mucho, y en ese instante gritaba a todos tanto en persa como en griego, que el Rey se aproximaba con un gran ejército preparado para la guerra..$^{29}$

Ciertamente no se especifica que el oficio de Pategías sea el de intérprete pero, si era uno de los allegados de Ciro, como apunta Jenofonte, no sería difícil suponer que en algún momento desempeñara esa función; como quiera que sea, valga este ejemplo para resaltar el bilingüismo greco-persa en el ejército de Ciro.

Falino, como se mencionó antes,${ }^{30}$ es un caso curioso de intérprete, pues, según noticias de Jenofonte, se trata de un griego experto en formación militar que estaba del lado del ejército persa de Tisafernes y quien, de acuerdo con Diodoro (XIV, 25, 1, ed. 2008), sería el encargado de recibir la capitulación de los griegos de Ciro. ${ }^{31}$ Afirmo que es un caso curioso porque es el único griego mencionado en la Anábasis que sabe la lengua persa y que, sin ser un intérprete profesional, cumple con esta función para comunicar a los persas de Tisafernes y a los griegos de Ciro, como puede comprenderse a partir de II, 1, 10-12, donde el contexto sugiere que el diálogo de ese momento se realiza en lengua persa y no en griego. ${ }^{32}$ Valga decir que Falino es

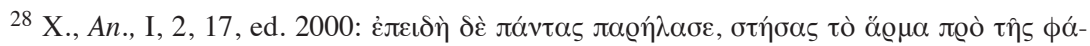

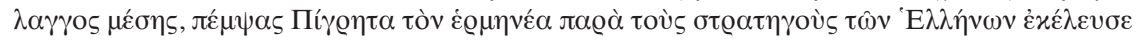

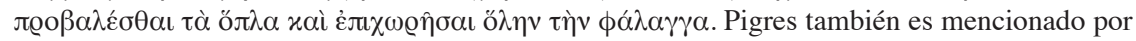
Jenofonte en I, 5, 7, y en I, 8, 12, aunque ahí no realiza su actividad profesional, sí se insiste en que es un intérprete al servicio de Ciro.

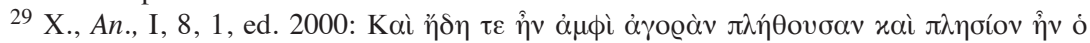

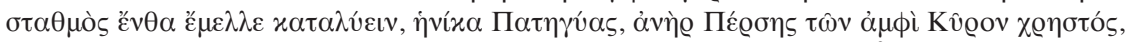

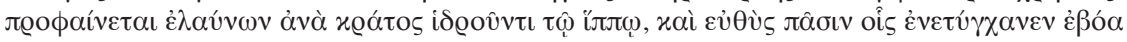

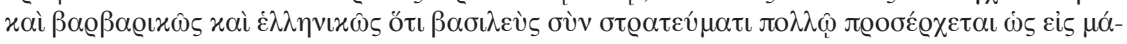

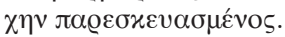

${ }^{30}$ Cf. nota 9.

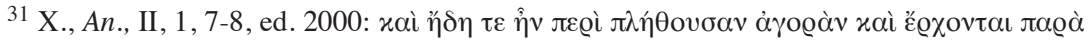

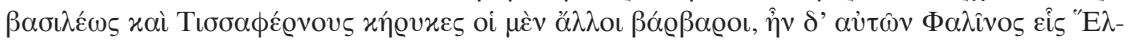

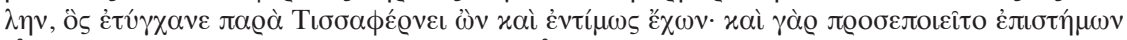

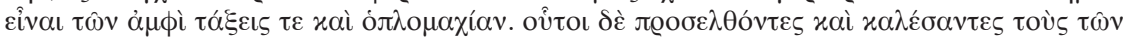

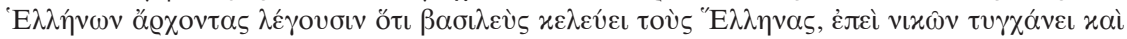

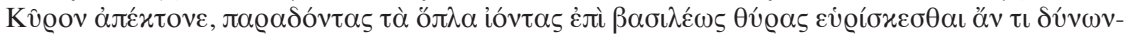
$\tau \alpha \iota \dot{\alpha} \gamma \alpha \theta$ óv.

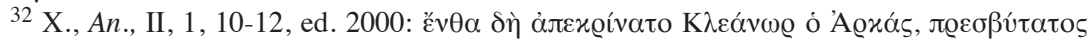

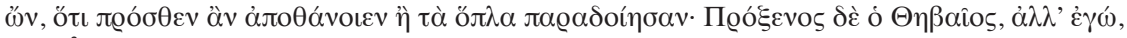

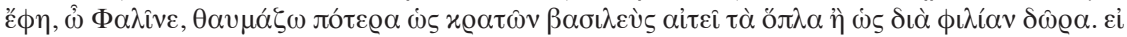


aludido varias ocasiones más en la Anábasis, y en todas aparece como un mediador militar, interlingüístico, entre griegos y persas.

Timesiteo era un patrono o próxeno que servía de intérprete de Jenofonte para mediar entre mosinecos y griegos, ${ }^{33}$ y Abrozelmes, el intérprete tracio al servicio personal de Seutes que traducía sus mensajes para Jenofonte; ${ }^{34}$ y el escanciador que sabe griego pero que sin ser un intérprete profesional, junto con Seutes, se mofa de las bromas que Aristas hace de Jenofonte durante un convite. ${ }^{35}$

A lo largo de la Anábasis hallamos otras referencias más a intérpretes de los que no se mencionan sus nombres. Por ejemplo, en II, 3, 17: "Cuando salieron a su encuentro los generales griegos, Tisafernes habló el primero, por medio de intérpretes, diciendo las siguientes palabras [...]". O en II, 5, 35: "Pero no llegaron todos, sino Arieo, Artaozo y Mitrídates, que habían sido los más fieles de Ciro. El intérprete de los griegos dijo que también veía y reconocía al hermano de Tisafernes con ellos [...]". Se señala en IV, 2, 17, que "los bárbaros, tras conseguir ese objetivo, coronaron la altura de enfrente del altozano en donde estaba Jenofonte, quien dialogó con ellos por medio de intérprete acerca de una tregua y les reclamó los cadáve-

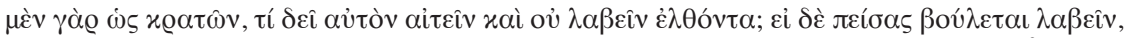

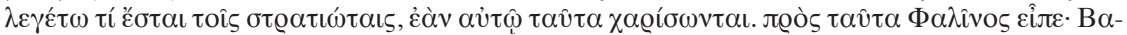

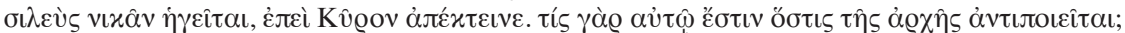

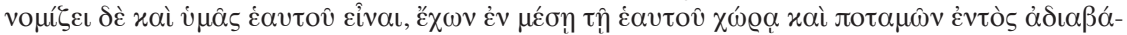

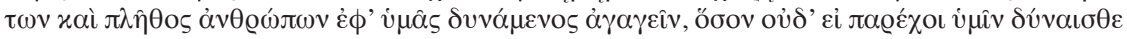

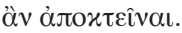

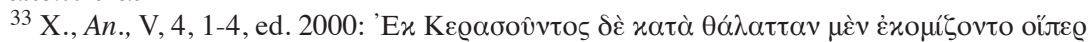

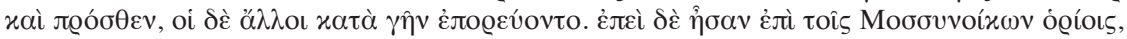

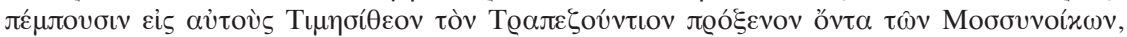

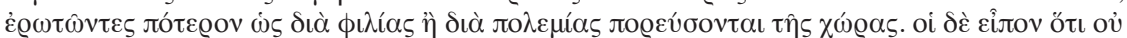

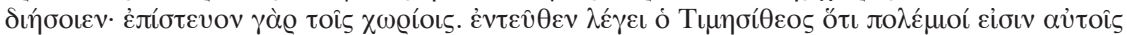

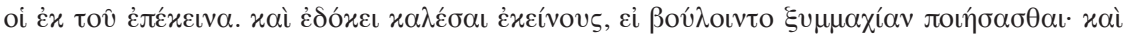

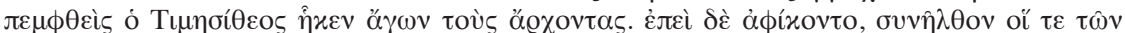

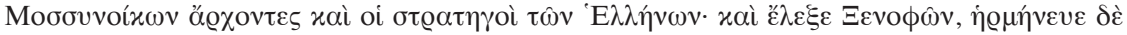

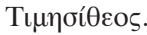

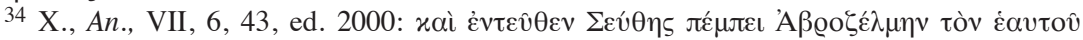

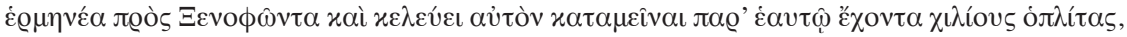

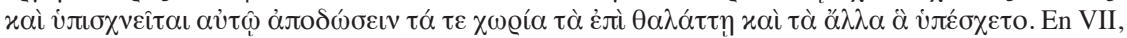
6,9 , Jenofonte hace notar que Seutes, aun cuando hacía uso de intérpretes para comunicarse,

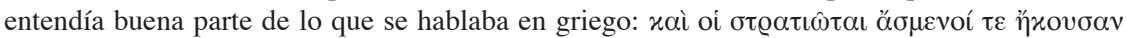

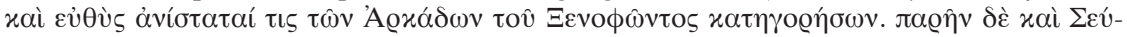

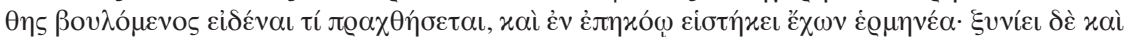

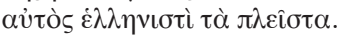

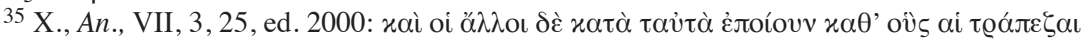

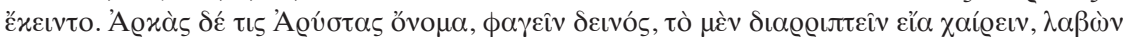

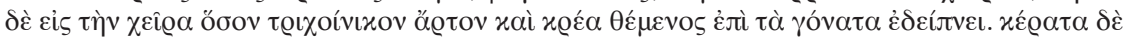

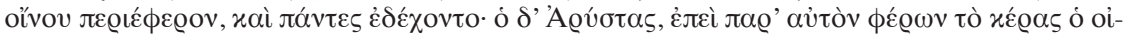

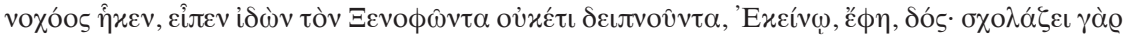

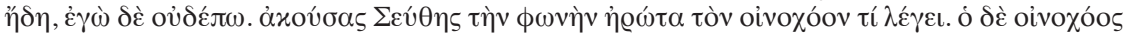

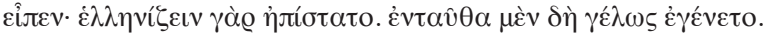


res". Al llegar a Armenia occidental, en IV, 4, 5, Jenofonte comenta que "Éste avanzó hacia ellos con unos jinetes y, mandando por delante a su intérprete, dijo que quería conversar con los jefes. Los generales decidieron escucharlo y, acercándose para poder oírlo, le preguntaron qué quería". Finalmente, en IV, 5, 10: "Estas mujeres les preguntaron quiénes eran. EI intérprete les dijo en persa que venía de parte del Rey a ver al sátrapa". En IV, 8, 4, tenemos el caso del soldado peltasta, muy posiblemente de origen macrón, que aseguraba haber sido esclavo en Atenas y que se ofrece como intérprete de Jenofonte para, como el mencionado Timesiteo, mediar entre él y los macrones que amenazaban a los griegos. La referencia a este personaje y la descripción que hace el propio Jenofonte de la operación interpretativa que ocurre en el preciso momento del diálogo entre griegos y macrones resulta interesante porque revela un proceso de traducción sucesiva:

Entonces un peltasta, que afirmaba haber sido esclavo en Atenas, se acerca a Jenofonte y le dice que sabe la lengua de los macrones: "creo", dice, "que esa es mi patria y si nada lo impide quiero hablar con ellos". Jenofonte le dice que nada lo impide y le pide que hable con ellos y les pregunte quiénes son. Ellos le responden que son macrones y Jenofonte pide preguntarles "por qué nos enfrentan y quieren ser nuestros enemigos". Y ellos le respondieron: "porque ustedes invadieron nuestro país". Los generales, entonces, le pidieron decirles que no les harían ningún daño pues "ya hemos peleado contra el Rey y ahora regresamos a Grecia y queremos llegar al mar". Los macrones preguntaron si les darían garantía de esto, y los griegos respondieron que se las darían pero que también las recibirían. Entonces los macrones dieron a los griegos una lanza bárbara y los griegos les dieron una griega afirmando que éstas era sus garantías, y unos y otros antepusieron a los dioses. ${ }^{36}$

Siguiendo el ejemplo anterior, otra situación de traducción oral en la que

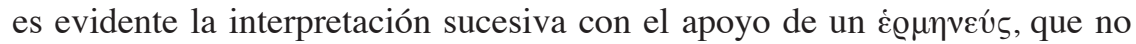
sabemos si es profesional o meramente incidental, la encontramos en IV, 5, 34: "Y después que Quirísofo y Jenofonte se abrazaron preguntaron al

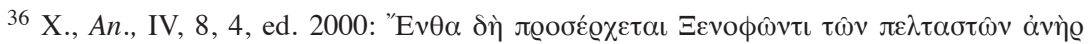

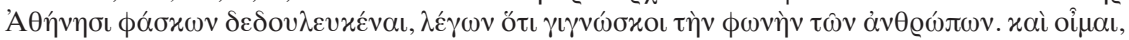

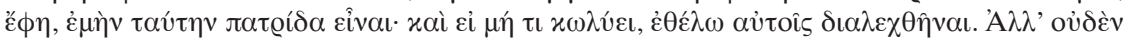

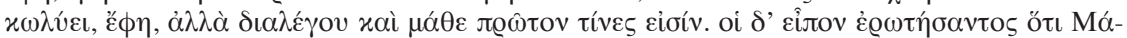

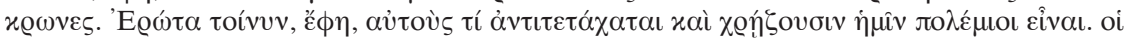

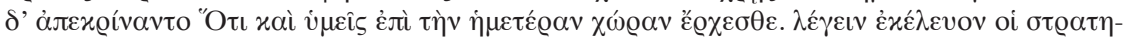

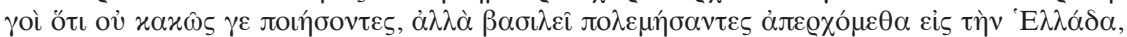

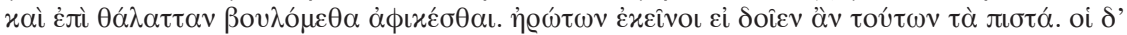

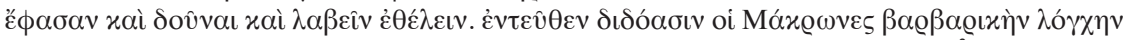

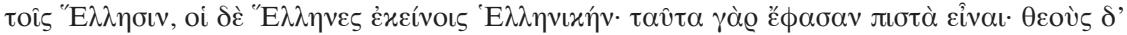

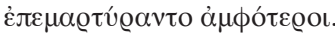


jefe de la aldea, por medio del intérprete de persa, qué país era ese, y él respondió que Armenia. Y le preguntaron de nuevo para quién se criaban los caballos, y él les respondió que eran un tributo para el Rey" ${ }^{37}$ Nótese la sucesión del diálogo mediante preguntas y respuestas en las que el intérprete es el mediador intercultural. Evidentemente estamos frente a un diálogo muy cotidiano, como debió haber muchos, entre griegos y bárbaros.

Hay varias referencias más o menos por el mismo estilo que, aun cuando hablan de la actividad interpretativa, no ayudan mucho a determinar la o

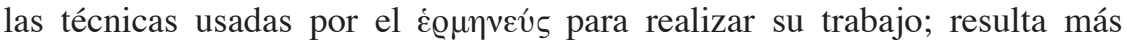
complicado saber si hacían las traducciones de manera simultánea, sucesiva o por susurro. Sin embargo, es factible pensar, como en el caso de Heródoto, que los intérpretes mencionados por Jenofonte también procedían de manera sucesiva, por pausas.

La traducción en susurro queda descartada, por lo menos en estos dos textos, toda vez que no hay referencias en ellos que permitan suponer que el intérprete se colocó detrás o a un lado de los interlocutores para hacer la traslación oral. La traducción simultánea también podría quedar eliminada, aun cuando hay al menos una o dos citas en Heródoto que podrían hacer pensar en ella, en I, 86, 6: "Creso dijo estas cosas a Ciro que las escuchaba de los intérpretes", y en III, 38, 4: "que seguían la conversación por medio de un intérprete [...]". No hay certeza. Además, cabe señalar que la traducción simultánea comienza a utilizarse de manera profesional sólo hasta 1945, durante el famoso juicio de Nuremberg en el que se procesó a los criminales de guerra nazis. ${ }^{38}$

Sin duda, es necesario realizar mayores y profundas investigaciones que revelen los métodos usados por estos intérpretes para realizar su trabajo de mediadores culturales, y que completen el panorama histórico de este tipo de traducción en la Antigüedad.

\section{CONCLUSIÓN}

Traducir no es fácil, nunca lo ha sido, y el oficio de traductor-intérprete tampoco lo es. Ser un traductor-intérprete es una actividad todavía más compleja que la del traductor literario. Éste todavía tiene tiempo para hacer una lectura más profunda, o varias, a fin de entender el sentido del texto, encontrar los equivalentes lingüísticos que considere más adecuados y trasladar el mensaje. El traductor-intérprete no. Las operaciones mentales que

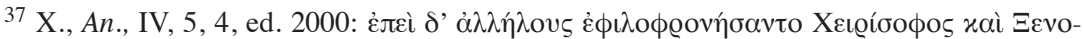

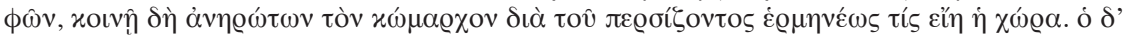

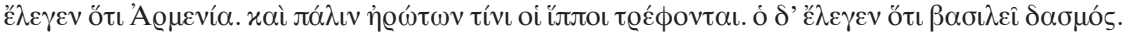

${ }^{38}$ Bellos 2012, pp. 250 y 285. 
efectúa para trasladar el mensaje entre lenguas son más rápidas sin importar el tipo de traducción oral que ejecute.

El intérprete debe poseer conocimientos avanzados de las lenguas que trabaja; tiene que conocer perfectamente bien sus estructuras gramaticales para emplearlas de manera oral en la transmisión de conceptos, procurando que las correspondencias seleccionadas conserven los respectivos matices y significados; además, debe mantener la certeza y veracidad del mensaje que está transmitiendo y respetar el estilo y el tono de los interlocutores que traduce.

No es segura, pues, la forma de proceder de los intérpretes griegos, que no eran griegos, sino más bien bárbaros, a excepción de Falino. Pero no por ello deben ser personajes desatendidos o casi olvidados. Antes bien, me parece necesario reconocer el enorme papel que jugaron para el desarrollo de las culturas antiguas, en particular de la griega. Sin ellos, quizá Heródoto no habría escrito sus Historias, o tal vez sí, pero con toda seguridad tendrían una forma e información diferentes; sin ellos, Creso no habría salvado su vida, Ciro no se habría comunicado con sus mercenarios griegos y Jenofonte no habría podido remontar las miles de parasangas de regreso a la Hélade.

\section{BIBLIOGRAFÍA}

\section{Fuentes antiguas}

DióDoro DE SicILIA, Biblioteca histórica libros XIII-XIV, Madrid, Gredos (Biblioteca Clásica Gredos), 2008.

Hérodote, Histoires, texte etab. et trad. Philippe-Ernest Legrand, Paris, Les Belles Lettres (Collection des Universités de France. Association Guillaume Budé), 1932-1954, 11 vols.

Heródoto, Historias III-IV, Madrid, Gredos (Biblioteca Clásica Gredos), 1979.

Plutarchi Vitae parallelae. Themistocles, vol. 1.1, ed. Konrat Ziegler, Leipzig, Teubner, 1969 (fourth edn.).

ThuCyDidis Historiae. Vol. 1. Libri I-II, ed. Otto Luschnat, Leipzig, Teubner, 1988.

Xenophon, Anabase, texte etab. et trad. Paul Masqueray, Paris, Les Belles Lettres (Collection des Universités de France. Association Guillaume Budé), 2000, 2 vols.

\section{Fuentes modernas}

Albaladejo, Manuel, "La imagen de los pueblos lejanos en la obra de Heródoto", Boletín de la Asociación Española de Orientalistas, 43, 2007, pp. 267-281. 
Bellos, David, Un pez en la higuera. Una historia fabulosa de la traducción, Madrid, Ariel, 2012.

García YeBra, Valentín, Traducción, historia y teoría, Madrid, Gredos (Biblioteca Hispánica Románica), 1994.

HARRISON, Thomas, "Herodotus' conception of foreing lenguajes", Histos, 2, 1998, pp. 1-45, https://research.ncl.ac.uk/histos/Histos_BackIssues1998.html (23/11/2019).

Hurtado Albir, Amparo, Traducción y traductología. Introducción a la traductología, Madrid, Editorial Cátedra (Lingüística), 2001.

JiménEZ, Francisco Javier, "Hijos de Babel: Una sinfonía inacabada", en Hijos de Babel. Reflexiones sobre el oficio de traductor en el siglo XXI, Madrid, Fórcola, 2013.

Jiménez Ivars, Amparo, La traducción a la vista. Un análisis descriptivo, tesis doctoral, Valencia, Universitat Jaume I-Facultat de Ciències Humanes i Socials, 1999.

Ortega Arjonilla, Emilio y Pedro San Ginés Aguilar, "Bibliografía especializada sobre traducción e interpretación: la Colección Interlingua de la Editorial Comares de Granada (1996-2009)", Entreculturas, 1, 2009, pp. 709-731, https:// dialnet.unirioja.es/servlet/articulo?codigo=4091990 (23/11/2019).

Signes Codoñer, Juan, Escritura y literatura en la Grecia arcaica, Madrid, Akal, 2004.

Steiner, George, Después de Babel. Aspectos del lenguaje y la traducción, México, Fondo de Cultura Económica, 2011.

$$
* * *
$$

José DAvid BecerRa Islas es maestro en Letras (Letras Clásicas) por la Universidad Nacional Autónoma de México. Es profesor de carrera en la Facultad de Filosofía y Letras de la UNAM, donde imparte las asignaturas de Griego I a VI, Teoría de la traducción aplicada a textos griegos e Historia de la traducción. Fue integrante del proyecto CONACYT "Filología, humanismo y tradición clásica. Problemas y perspectivas comunes" y del proyecto PAPIME EN402603 "Elaboración de materiales didácticos para los alumnos de Letras Clásicas". Fue responsable del proyecto PAPIME EN401010 "Materiales didácticos para la enseñanza del griego clásico en la FFYL" y actualmente encabeza el proyecto PAPIME 401415 "Materiales didácticos para la enseñanza del griego antiguo y su traducción" en la FFYL. Sus áreas de investigación son la filosofía neoplatónica, particularmente la de Porfirio de Tiro, el conflicto religioso entre cristianos y paganos de los siglos III y IV, y la Historia de la traducción y la traductología de textos griegos antiguos. 